\title{
Uterine Monitoring Techniques from Patients' and Users' Perspectives
}

\author{
Kirsten M. J. Thijssen, MD ${ }^{1,2}$ Marion W. C. Vlemminx, MD ${ }^{1,2}$ Michelle E. M. H. Westerhuis, MD, PhD ${ }^{1}$ \\ Jeanne P. Dieleman, $\mathrm{PhD}^{3}$ \\ M. Beatrijs Van der Hout-Van der Jagt, $\mathrm{PhD}^{1,2}$ \\ S. Guid Oei, MD, PhD ${ }^{1,2}$ \\ 1 Department of Obstetrics and Gynecology, Máxima Medical Center,
Veldhoven, the Netherlands
${ }^{2}$ Department of Electrical Engineering, Eindhoven University of
Technology, Eindhoven, the Netherlands
${ }^{3}$ MMC Academy, Máxima Medical Center, Veldhoven, the Netherlands \\ Address for correspondence Kirsten M. J. Thijssen, MD, \\ Department of Obstetrics and Gynecology, Máxima Medical Center, \\ PO Box 7777, 5500MB, Veldhoven, the Netherlands \\ (e-mail: kirsten.thijssen@mmc.nl).
}

Am J Perinatol Rep 2018;8:e184-e191.

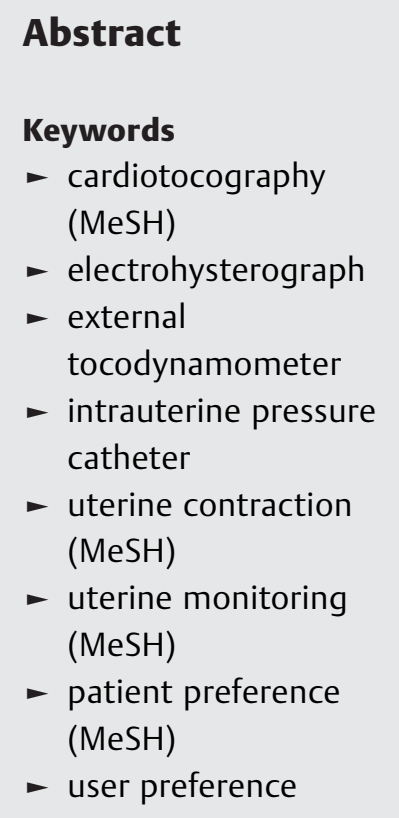

Objective To evaluate preferences from patients and users on 3 uterine monitoring techniques, during labor.

Study Design Women in term labor were simultaneously monitored with the intrauterine pressure catheter, the external tocodynamometer, and the electrohysterograph. Postpartum, these women filled out a questionnaire evaluating their preferences and important aspects. Nurses completed a questionnaire evaluating users' preferences.

Results Of all 52 participating women, $80.8 \%$ preferred the electrohysterograph, $17.3 \%$ the intrauterine pressure catheter and $1.9 \%$ the external tocodynamometer. For these women, the electrohysterograph scored best regarding application and presence during labor $(p<0.001)$. Most important aspects were "least likely to harm" and "least discomfort". Of 57 nurses, $40.4 \%$ preferred the electrohysterograph, 35.1\% the external tocodynamometer, and $24.6 \%$ had no preference, or replied that their preference is subject to situation and patient.

Conclusion Patients prefer the electrohysterograph over the external tocodynamometer and the intrauterine pressure catheter, while healthcare providers report ambiguous results.
Annually, more than 5 million women give birth in the European Union. Most of them receive uterine monitoring during labor through the external tocodynamometer (TOCO), the intrauterine pressure catheter (IUPC), or the electrohysterograph (EHG). These techniques are compared in several studies that mainly focus on diagnostic values, interpretability, and labor outcomes. ${ }^{1-5}$ Only 1 article describes patients' and users' (i.e., healthcare provider) satisfaction of 2 securing methods (belts), both concerning external TOCO devices. ${ }^{6}$ Reports on users' and patients' preferences of all 3 uterine monitoring methods are still missing, while this topic is becoming more important nowadays.

received

March 26, 2018

accepted after revision

July 21,2018
DOI https://doi.org/

10.1055/s-0038-1669409.

ISSN 2157-6998.
Each uterine monitoring technique has advantages and limitations from patients' and users' perspectives. For example, TOCO measures changes of the abdominal wall noninvasively. It is generally applied by nursing staff and wireless connections are developed. A problem of this abdominal transducer is signal loss following maternal movements. With TOCO, a significant period of absent uterine activity monitoring (complete signal loss in 20 out of 42 minutes of registration) is described. ${ }^{7}$ To obtain a continuous registration of good quality, this method requires frequent repositioning of the transducer and tightening of the abdominal elastic belt. The alternative external method, EHG, measures
Copyright $\odot 2018$ by Thieme Medical Publishers, Inc., 333 Seventh Avenue, New York, NY 10001, USA. Tel: +1(212) 584-4662.
License terms

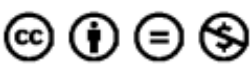


uterine electrical activity noninvasively by abdominal electrodes that can be applied by the nursing staff. ${ }^{8}$ Due to the adhesive properties, these electrodes are potentially lessmotion-sensitive than TOCO. For EHG, reduction of the skin impedance with abrasive sandpaper is necessary for proper data acquisition and the abdominal patch needs to be removed after the delivery. ${ }^{9}$ The current gold standard, IUPC, provides a direct and accurate measurement of the pressure changes inside the uterine cavity. Therefore, it can only be used, when the membranes are ruptured. ${ }^{10}$ Moreover, severe IUPC related complications have been described, such as placental or uterine wall perforation. ${ }^{11}$ In addition, the invasive IUPC needs to be inserted by experienced obstetricians or midwives, who might not always be available.

In a separate paper, we described a study with simultaneous recordings of EHG, TOCO, and IUPC. ${ }^{5}$ Apart from the presented test characteristics, we wanted to gain insight into the patients' and users' preferences and characteristics, as well as they should be considered, when opting for uterine monitoring techniques. We hypothesize that both patients and users prefer EHG, since this method is noninvasive and less influenced by maternal movements.

\section{Materials and Methods}

We performed a prospective diagnostic accuracy study in the Máxima Medical Center, Veldhoven, the Netherlands. Term pregnant women carrying a singleton fetus in cephalic presentation were included. Once in active labor, eligible women were simultaneously connected to TOCO, IUPC, and EHG for 2 hours. Per patient we used 3 identical cardiotocography (CTG) monitors (Avalon FM30, Philips Healthcare, Eindhoven, the Netherlands) to store each real-time tocogram in the Electronic Patient System (Ezis, Chipsoft, Amsterdam, the Netherlands).

First, after ultrasound localization of the placenta and during vaginal examination, a flexible sensor-tipped IUPC (Koala, Clinical Innovations, Murray, Utah, USA) was inserted in the amniotic cavity. This was done by an experienced physician or midwife, in presence of 1 of the researchers that checked proper placement after connection. Second, 1 of the researchers prepared the abdominal skin by abrasive paper to reduce skin impedance, and positioned the EHG patch (Graphium, Nemo Healthcare, Eindhoven, the Netherlands). The skin impedance was checked with the impedance meter (SIGGI II, MedCaT, Klazienaveen, the Netherlands). The preparation was considered adequate, when values were below $5 \mathrm{k} \Omega$. The EHG patch was then connected to the translation module for data processing (PUREtrace, Nemo Healthcare, Eindhoven, the Netherlands). Third, TOCO was placed at the uterine fundus and tied up with an elastic belt. For logistic reasons, TOCO was wirelessly connected to the CTG monitor. The researchers were present during each measurement, lasting from 30 minutes up to 2 hours, to annotate adjustments to any of the 3 techniques. TOCO signal quality was checked by the attending nurses every 30 minutes and the position of the TOCO was adjusted, if necessary. After 2 hours, we removed TOCO and EHG, while IUPC remained in place until the end of the delivery.

Evaluation of patients' preferences was performed by a questionnaire filled out by the participating women within a few hours postpartum. The survey entailed 3 identical continuous scale questions for each uterine monitoring technique (IUPC, TOCO, and EHG) with a $100 \mathrm{~mm}$ scale corresponding to "not bothering at all" $(0 \mathrm{~mm})$ to "very bothering" (100 mm) regarding: (1-3) positioning, (4-6) presence during labor, and (7-9) removal. The actual value of the scale was not visible for the participants, but was calculated by the researchers afterwards. Additionally, this identical 0 to $100 \mathrm{~mm}$ scale was used to assess: (10) skin preparation for EHG and (11) transducer modifications during labor for TOCO. The survey entailed 4 multiple choice questions: (12) which of the 3 methods women preferred (EHG, TOCO, IUPC); (13) which factors of both external methods they considered as being most important (least difficult to position, least discomfort, least adjustments, least limitation of mobility, or least difficult to remove); (14) which external method women preferred (scale -50 to +50 , corresponding to -50 for TOCO, 0 for neutral, and +50 for EHG); and (15) which aspects of uterine monitoring (either internal or external) they considered as being most important (costs, quality, discomfort, or potential harm). We also asked our participants, whether they experienced irritation, pain, discomfort, or dislocations with either 1 of the techniques. Finally, the women had the opportunity to leave other remarks or notes.

After completion of the validation study, EHG was introduced as standard alternative in our clinic. In case, TOCO was inadequate, EHG was applied by obstetric nurses that were trained by the main researchers on correct application. To evaluate user satisfaction, we asked all obstetric nurses that had been working with EHG, to fill out a questionnaire. This questionnaire entailed 9 continuous scale questions from 1 to 5, regarding their experiences with EHG: (1) sufficient knowledge of EHG, (2) sufficient competence with EHG, (3) usefulness of uterine palpation, (4) inconvenience due to performing skin preparation, (5) frequency of performing uterine palpation, (6) frequency of using the impedance meter, (7) repeating skin preparation, when the skin impedance is above $5 \mathrm{k} \Omega$, (8) installing EHG without technical problems, (9) the prevalence of local skin irritation. The 5point scale corresponded to 1 = "agree" and $5=$ "disagree" for questions 1 to 3 , to $1=$ "very bothering" and $5=$ "not bothering" for question 4 , and to $1=$ "always" and $5=$ " never" for questions 5 to 9 .

Furthermore, this user questionnaire entailed 6 additional questions regarding their experiences with external uterine monitoring techniques: (10) which technique is more time-consuming (TOCO, EHG, or no difference); (11) method of preference (TOCO, EHG, or no preference); (12) advantages of EHG (open question); (13) disadvantages of EHG (open question); (14) recommendation of EHG to colleagues working in another hospital, (rated from $0=$ "not likely" to 10 = "very likely"); (15) frequency of weekly EHG usage in clinical practice (open question). For every question, there was the opportunity to write comments. 


\section{Statistical Analysis}

The sample size of 52 patients was based on a power analysis to validate the sensitivity of EHG, reported in our previous publication. ${ }^{5}$ We used SPSS (Statistical Package for Social Science) 23 statistics (IBM, New York, USA) for statistical evaluation. Descriptive statistics included frequencies with percentages and $95 \%$ confidence intervals $(\mathrm{CI})$ for categorical data, ${ }^{12,13}$ mean with standard deviation (SD) for normally distributed continuous variables, or median with interquartile range (IQR) for nonnormally distributed continuous variables. Normality was checked visually using histograms, in addition to values for skewness and kurtosis between -1 and +1 . Statistical significance was accepted at a 2-sided $p$-value below 0.05 .

The results of the continuous scale questions regarding the placement, presence during labor and removal of the equipment were tested with the Wilcoxon's signed rank test for paired data, when comparing 2 techniques. The Friedman's test was used, when comparing all 3 techniques together. The patients' preferences for either 1 of the 3 techniques were tested by the Chi-squared test. Additionally, the patients' preferences were compared in subgroups based on obesity and labor analgesia. We hypothesized that patients without labor analgesia prefer TOCO over EHG and IUPC, because its wireless connection enables patients' mobility. Obese women might prefer IUPC over the external methods, as their increased abdominal adipose tissue significantly hampers their pregnancy and labor surveillance. These subgroup comparisons were tested with the Fisher's Exact test.

Frequencies, percentages, and 95\%CI regarding users' preferences were calculated. ${ }^{12,13}$ For calculation of cumulative percentages, score 1 (totally agree) and 2 (agree) were summed up, or score 4 (disagree) and 5 (totally disagree).

\section{Ethical Approval}

The Institutional Review Board of Máxima Medical Center approved the protocol on 15 July 2014 (NL48951.015.14) and the study is registered in the Dutch trial register (NTR5894), http://www.trialregister.nl/trialreg/admin/rctview.asp? $\mathrm{TC}=5894$.

Pregnant women were recruited in Máxima Medical Center (Veldhoven, the Netherlands). All measurements were performed by 2 researchers (K.M.J.T. and M.W.C.V), after informed consent was received.

\section{Results}

\section{Patients' Preferences}

From July 2014 to June 2016, 52 women participated in our study. All questionnaires were completed within 24 hours postpartum, except for 1 which was filled out within 1 week after the delivery. No questionnaires were lost to follow-up. Six patients did not fill out all questions regarding "the presence" ( 4 women) or "the removal" ( 2 women) of the 3 uterine monitoring techniques, therefore impeding comparison of these paired measurements. In addition, 1 woman did not answer the questions regarding the most important factor of the external methods. The patient characteristics are presented in $\boldsymbol{-}$ Table $\mathbf{1}$.
Table 1 Sociodemographic and clinical characteristics of 52 women simultaneously monitored with the electrohysterograph, external tocodynamometer and intrauterine pressure catheter

\begin{tabular}{|c|c|}
\hline Characteristic & $n=52$ \\
\hline Maternal age $(y)$ & $31.7 \pm 4.3$ \\
\hline \multicolumn{2}{|l|}{ Race } \\
\hline Caucasian & $48(92.3 \%)$ \\
\hline Other & $4(7.7 \%)$ \\
\hline \multicolumn{2}{|l|}{ Parity } \\
\hline Nulliparous & $29(55.8 \%)$ \\
\hline Multiparous & $23(44.2 \%)$ \\
\hline Gestational age $(w k+d)$ & $39.3 \pm 8.1$ \\
\hline \multicolumn{2}{|l|}{ Body mass index (BMI, $\left.\mathrm{kg} / \mathrm{m}^{2}\right)$} \\
\hline Before pregnancy & $29.2 \pm 8.1$ \\
\hline During measurement $^{a}$ & $33.8 \pm 7.4$ \\
\hline \multicolumn{2}{|l|}{ Start of labor } \\
\hline Spontaneous onset & $16(30.8 \%)$ \\
\hline Induction of labor & $36(69.2 \%)$ \\
\hline \multicolumn{2}{|l|}{ Oxytocin usage } \\
\hline No & $14(26.9 \%)$ \\
\hline Yes & $38(73.1 \%)$ \\
\hline \multicolumn{2}{|l|}{ Labor analgesia } \\
\hline No analgesia & $15(28.9 \%)$ \\
\hline Epidural analgesia & $34(65.4 \%)$ \\
\hline Remifentanil & $3(5.8 \%)$ \\
\hline Duration measurement (min) & $104.4 \pm 29.1$ \\
\hline \multicolumn{2}{|l|}{ Cervical dilatation $(\mathrm{cm})$} \\
\hline Start measurement & $4.0(3-10)$ \\
\hline Stop measurement & $8.5(3-10)$ \\
\hline \multicolumn{2}{|l|}{ Mode of delivery } \\
\hline Spontaneous vaginal delivery & $36(69.2 \%)$ \\
\hline Vacuum delivery & $7(13.5 \%)$ \\
\hline Cesarean section & $9(17.3 \%)$ \\
\hline
\end{tabular}

Note: Data are mean \pm standard deviation, median (range), $n$, or $n(\%)$ unless otherwise specified.

${ }^{\mathrm{a}}$ In 3 women, body mass indices during labor are missing (values of 20 , 42 and 48 before pregnancy).

Of the 52 women, 42 (80.8\%; $95 \%$ CI; $68.4-89.8 \%)$ preferred uterine monitoring by EHG, 9 women $(17.3 \%$; $95 \%$ CI; $8.8-29.4 \%$ ) preferred IUPC, and 1 woman (1.9\%; $95 \%$ CI; 0.1-9.1\%) preferred TOCO. This result was tested as a significant difference ( $\boldsymbol{-}$ Table 2 ). The subgroup comparisons based on obesity (nonobese or obese) and labor analgesia (none, epidural analgesia or remifentanil) reported no significant differences regarding the preferences of the women (-Table 2). Furthermore, we asked the women to choose between one of the external methods based on a continuous scale from -50 for TOCO to +50 for EHG. This revealed a strong preference for EHG, with an average score of 38.7. 
Table 2 Patients' preferences regarding uterine monitoring techniques

\begin{tabular}{|c|c|c|c|c|}
\hline & IUPC & TOCO & EHG & Significance \\
\hline $\begin{array}{l}\text { Overall } \\
(n=52)\end{array}$ & $\begin{array}{l}9 \\
(17.3 \%)\end{array}$ & $\begin{array}{l}1 \\
(1.9 \%)\end{array}$ & $\begin{array}{l}42 \\
(80.8 \%)\end{array}$ & $p=<0.001^{a}$ \\
\hline \multicolumn{5}{|c|}{ Maternal obesity } \\
\hline $\begin{array}{l}\text { Nonobese } \\
(n=20)\end{array}$ & $\begin{array}{l}5 \\
(25.0 \%)\end{array}$ & $\begin{array}{l}0 \\
(0.0 \%)\end{array}$ & $\begin{array}{l}15 \\
(75.0 \%)\end{array}$ & \multirow[t]{2}{*}{$p=0.452^{b}$} \\
\hline $\begin{array}{l}\text { Obese } \\
(n=32)\end{array}$ & $\begin{array}{l}4 \\
(12.5 \%)\end{array}$ & $\begin{array}{l}1 \\
(3.1 \%)\end{array}$ & $\begin{array}{l}27 \\
(84.4 \%)\end{array}$ & \\
\hline \multicolumn{5}{|l|}{ Labor analgesia } \\
\hline No $(n=15)$ & $\begin{array}{l}1 \\
(6.7 \%)\end{array}$ & $\begin{array}{l}1 \\
(6.7 \%)\end{array}$ & $\begin{array}{l}13 \\
(86.6 \%)\end{array}$ & \multirow[t]{3}{*}{$p=0.226^{b}$} \\
\hline $\begin{array}{l}\text { Epidural } \\
(n=34)\end{array}$ & $\begin{array}{l}7 \\
(20.6 \%)\end{array}$ & $\begin{array}{l}0 \\
(0.0 \%)\end{array}$ & $\begin{array}{l}27 \\
(79.4 \%)\end{array}$ & \\
\hline $\begin{array}{l}\text { Remifentanil } \\
(n=3)\end{array}$ & $\begin{array}{l}1 \\
(33.3 \%)\end{array}$ & $\begin{array}{l}0 \\
(0.0 \%)\end{array}$ & $\begin{array}{l}2 \\
(66.7 \%)\end{array}$ & \\
\hline
\end{tabular}

Note: Data are $n$ (\%); maternal obesity was defined as a body mass index of $\geq 30 \mathrm{~kg} / \mathrm{m}^{2}$ during labor.

${ }^{a}$ Chi-squared test.

'Fisher's Exact test.

On a continuous scale from 0 to 100 , "application of EHG" was scored as being least bothering, with significant differences between all 3 methods (-Table 3 ). Regarding the "presence during labor", patients were significantly more bothered by TOCO than by IUPC or EHG. No significant differences were found between the 3 methods regarding "removal of equipment”. However, when EHG was only compared with TOCO, we did find a significant difference in favor of TOCO (-Table 3). The discomfort due to the skin preparation required for EHG was assessed as minor, with a median of 6.6 (IQR; $2.0-21.9$ ), although 8 patients (15.4\%) did report local irritation due to skin preparation and/or the abdominal EHG patch. In comparison, local skin irritation with TOCO was reported by only 3 women (5.8\%). Several women complained about discomfort (23.1\%) and dislocations (28.8\%) of TOCO, which was not reported for EHG. For IUPC, 3 women (5.8\%) reported dislocations, 2 women (3.8\%) experienced discomfort and 1 woman (1.9\%) experienced pain.

Considering uterine monitoring in general (internal and external), "least likely to harm" was reported as most important factor by $51.9 \%$ of the women, "best quality" by $25.0 \%$ and "least discomfort" by $23.1 \%$. Furthermore, when considering the characteristics of the external methods $(n=51)$, $60.8 \%$ of the participants considered "least discomfort" as an important factor for external uterine monitoring, followed by "least limitation of mobility" with $27.5 \%$, "least difficult to position" with $5.9 \%$ and "least adjustments" with $5.9 \%$.

\section{Users' Preferences}

In April 2017, all obstetric nurses that had been working with EHG (57 nurses, 100\%) completed the questionnaire concerning user satisfaction. Of them, 23 nurses (40.4\%; 95\% CI; 28.2-53.4\%) chose EHG as preferred external method, compared with 20 nurses (35.1\%; 95\% CI; 23.6-48.1\%) choosing TOCO. Furthermore, 14 nurses (24.6\%; 95\% CI; 14.7-36.9\%) had no preference or replied that their preference was subject to situation and patient.

Regarding their experiences with EHG on a 5-point scale, $67.3 \%$ of nurses reported that they had sufficient knowledge about EHG (mean $2.1 \pm 1.3$ ) and $73.7 \%$ of all nurses considered themselves as competent in the use of EHG (mean $2.2 \pm 1.0$ ). Most nurses also confirmed that they palpate the uterus to ensure optimal localization of EHG (subdivided into helpfulness $87.3 \%$ [mean $1.6 \pm 1.0$ ] and frequency $86.8 \%$ [mean $1.6 \pm 1.0$ ]). Only $13.2 \%$ of nurses reported to use the impedance meter to check the impedance after skin preparation (mean $4.4 \pm 1.2$ ). However, the nurses that do use the impedance meter also repeat skin preparation, when the impedance appeared to be too high (mean $1.5 \pm 0.7$ ). Most nurses $(71.7 \%$ ) reported no problems with application of this EHG system (mean $2.1 \pm 0.8$ ). EHG was considered most time-consuming by $60.4 \%$ of nurses, compared with $22.6 \%$ that found TOCO more time-consuming, the remaining $17.0 \%$ was neutral. The users' questionnaire revealed indifferent results regarding the inconvenience of skin preparation

Table 3 Assessment of the application, presence and removal of intrauterine pressure catheter (IUPC), external tocodynamometer (TOCO) and electrohysterograph (EHG)

\begin{tabular}{|c|c|c|c|c|c|}
\hline & IUPC & TOCO & EHG & Significance & Significance \\
\hline $\begin{array}{l}\text { Application } \\
(n=52)\end{array}$ & $\begin{array}{l}30.6(8.0-53.1) \\
30.6(8.0-53.1) \\
-\end{array}$ & $\begin{array}{l}10.0(2.1-27.6) \\
- \\
10.0(2.1-27.6)\end{array}$ & $\begin{array}{ll}- & \\
2.1 & (0.0-5.2) \\
2.1 & (0.0-5.2)\end{array}$ & $\begin{array}{l}p<0.001^{a} \\
p<0.001^{a} \\
p<0.001^{a}\end{array}$ & $p<0.001^{b}$ \\
\hline $\begin{array}{l}\text { Presence } \\
(n=48)\end{array}$ & $\begin{array}{l}8.3(1.0-47.0) \\
8.3(1.0-47.0) \\
-\end{array}$ & $\begin{array}{l}42.0(10.8-58.7) \\
- \\
42.0(10.8-58.7)\end{array}$ & $\begin{array}{ll}- & \\
2.1 & (0.0-6.5) \\
2.1 & (0.0-6.5)\end{array}$ & $\begin{array}{l}p=0.004^{a} \\
p<0.001^{a} \\
p<0.001^{a}\end{array}$ & $p<0.001^{b}$ \\
\hline $\begin{array}{l}\text { Removal } \\
(n=50)\end{array}$ & $\begin{array}{l}5.2(1.0-15.0) \\
5.2(1.0-15.0) \\
-\end{array}$ & $\begin{array}{l}3.1(0.0-9.0) \\
- \\
3.1(0.0-9.0)\end{array}$ & $\begin{array}{l}- \\
10.0(2.1-22.9) \\
10.0(2.1-22.9)\end{array}$ & $\begin{array}{l}p=0.052^{a} \\
p=0.583^{a} \\
p=0.011^{a}\end{array}$ & $p=0.188^{b}$ \\
\hline
\end{tabular}

Note: Data are median with (interquartile ranges); the continuous scale ranged from 0 to 100 , corresponding to "not bothering at all" to "very bothering."

aWilcoxon's signed rank test.

bFriedman's test. 
(mean $3.4 \pm 1.2$ ) and local irritation due to EHG (mean of $3.3 \pm 1.0$ ), whereas in the open answers $35.1 \%$ of the nurses observed skin redness and 19.3\% skin irritation.

The most reported advantage of EHG was a more constant and reliable registration, which especially holds in case of obesity and with changing maternal position $(64.9 \%$ of the respondents). In addition, $24.6 \%$ of the nurses considered the improved patient satisfaction to be an advantage. The main disadvantage, reported by $54.4 \%$ of the nurses, was a decreased mobility of patients by cables of EHG. The fact that this EHG method cannot be used in bath or shower was reported as a disadvantage by $28.1 \%$ of the nurses. Finally, the users would recommend this EHG method to colleagues with a score of $6.3 \pm 2.0$ out of 10 .

\section{Discussion}

This is the first study evaluating patients' and users' preferences of 3 uterine monitoring techniques; the internal IUPC, which is the current gold standard though not routinely used, the external TOCO, which is the method of first choice, ${ }^{14-16}$ and external EHG that was only recently validated for contraction monitoring. ${ }^{5}$ Patients strongly preferred EHG over TOCO and IUPC. EHG is considered as the most comfortable method regarding both placement and presence during labor. On the contrary, preferences of healthcare providers were ambiguous.

A strength of the evaluation on patients' preferences is the unique situation: all patients received all 3 methods, so they are most eligible to evaluate their preferences. Another strength of our study is that we had little missing data. Almost all women filled out the questionnaires directly postpartum or within a few hours, which resulted in a complete database. We also had a high response rate to evaluate users' preferences as every obstetric nurse completed the questionnaire.

One limitation of this study was that there were no validated questionnaires available to evaluate neither patients' nor users' preferences on uterine monitoring techniques, so we developed customized questionnaires for this purpose. Another limitation might be that we collected the patients' questionnaire this short after a life-event, which could influence the outcomes. However, we expect that the mutual comparison is minimally affected, since the comparison includes all 3 methods applied to the same woman at the same time. Finally, both patients and users were aware that EHG was the newly introduced technique, which may have caused bias.

\section{Safety}

One of the main principles in medicine is "primum non nocere", i.e first do no harm. ${ }^{17}$ Our results underline this statement as most women preferred the aspect "least likely to harm" above comfort, quality and costs.

On the one hand, noninvasive external monitoring methods are therefore preferred above invasive methods to monitor the uterine activity pattern.

Extra membranous placement of IUPC is not uncommon (reported incidence is 23-38\%) and potential risks following improper IUPC placement include perforation of the placenta, the uterus, or fetal blood vessels. ${ }^{11,18}$ However, a Cochrane review reported no major complications in 977 women being exposed to IUPC. ${ }^{1}$ Therefore, IUPC-related complications are rare, yet can be very severe.

On the other hand, inadequate external uterine monitoring could also be considered as unsafe for mother and child. The widely used TOCO is noninvasive but has a low reported sensitivity: from 46 to $74 \%$ thereby missing a significant number of contractions. ${ }^{19,20}$ EHG has a significant higher reported sensitivity: from 86 to $98 \%{ }^{3-5,19-21}$ Inadequate uterine monitoring can result in fetal distress and cesarean delivery due to insufficient relaxation time to reoxygenate the placental tissue in case of (missed) hypertonia or hyper stimulation of the uterus. ${ }^{22,23}$ Especially during induction or augmentation of labor, the uterine activity pattern should be closely monitored to improve the safety of not only mother and child, ${ }^{16}$ but also of the obstetrical caregiver, as oxytocin is often involved in obstetric litigation. ${ }^{24}$

\section{Comfort}

Of the external methods, patients preferred the technique with the "least discomfort" (60.8\%) during labor above mobility, adjustments, positioning, and removing. TOCO required frequent adjustments during labor, such as repositioning of the transducer and tightening of the elastic belt, resulting in discomfort reported by $23.1 \%$ of our participants. Patients also reported to be least bothered by the presence of EHG during labor compared with TOCO and IUPC. However, a potential discomfort of EHG could be temporarily skin reactions following skin preparation and/or the abdominal patch, which has been reported by $15.4 \%$ of patients. Another issue concerning comfort is for the equipment to be waterproof, in case patients prefer having a bath or shower during labor. The studied EHG method was not waterproof, and IUPC catheters were also not suitable for use in water. The telemetry variant of TOCO could be used in both shower and bath, and is therefore most suitable for these patients. When waterproof EHG methods will be available, patients' comfort could be further improved.

\section{Mobility}

Next to comfort, our participants considered mobility as an important factor during labor. Research has also shown that walking and upright positions positively influence the progress of labor. ${ }^{25}$

With IUPC, mobility is seriously hampered as these women are confined to bed because the catheter can fall out, when they walk around. Eight out of 9 (88.9\%) women that chose IUPC as their preferred method, had labor analgesia and were thus being confined to bed already. Both external methods (EHG and TOCO) can provide more mobility than IUPC. Cables for both EHG and TOCO are long enough to walk around the bed but mobility is still compromised. Therefore, wireless connections are preferred to further improve mobility. TOCO can be wireless (although not all hospitals have the availability of wireless systems), while most real-time EHG systems do not (yet) provide wireless connections. On the contrary, EHG can enhance mobility 
during labor compared with TOCO due to the adhesive properties of the contact electrodes, which are less sensitive to position.

\section{Time-Efficiency}

Novel techniques used at the labor ward should not only be preferred by patients, but should also be user-friendly. The results of our user questionnaire revealed ambiguous results, regarding their preference for EHG (40.4\%) or TOCO (35.1\%). Less experienced nurses found the use of EHG more timeconsuming than TOCO. Especially, the impedance meter was considered as difficult to use and a time-consuming step to integrate in clinical practice. However, Euliano et al suggested that the usage of EHG could reduce nursing time. ${ }^{19}$
Our more experienced nurses also recognized the timesaving aspect of EHG as it needs to be applied only once per patient, due to its adhesive properties. Thus, while initiating the measurement might be more time-consuming, this could be compensated by reduced interference time during the measurement. In contrast, TOCO needs to be repositioned several times during labor, especially after maternal movements. To assess this hypothesis, we annotated all adjustments during the measurements. We checked signal quality every 30 minutes during the 2-hour registration period: on average, TOCO needed to be repositioned twice due to signal loss. Within the same time frame, EHG required 1 adjustment on average such as calibration or reset baseline (zero) on the CTG monitor. IUPC required less

Table 4 Advantages and limitations of currently available uterine monitoring techniques

\begin{tabular}{|c|c|c|c|}
\hline Technical characteristics: & $\begin{array}{l}\text { Intrauterine pressure } \\
\text { catheter (IUPC) }\end{array}$ & $\begin{array}{l}\text { External tocodynamometer } \\
\text { (TOCO) }\end{array}$ & Electrohysterograph (EHG) \\
\hline Used technique & $\begin{array}{l}\text { Sensor-tipped or transducer } \\
\text { catheters measuring changes } \\
\text { of the intrauterine pressure }\end{array}$ & $\begin{array}{l}\text { Gauge transducer measuring } \\
\text { shape changes of the } \\
\text { abdominal wall }\end{array}$ & $\begin{array}{l}\text { Abdominal electrodes } \\
\text { measuring the electrical } \\
\text { activity of the uterine muscle }\end{array}$ \\
\hline Value of the measurement & Millimeters of mercury & Relative TOCO units & MicroVolts \\
\hline Internal or external & Internal & External & External \\
\hline Invasiveness & Invasive & Noninvasive & Noninvasive \\
\hline Application of technique & During vaginal examination & Abdominal positioning & Abdominal positioning \\
\hline Placed by & Only physicians or midwives & Any obstetrical caregiver & Any obstetrical caregiver \\
\hline Reusability & Disposable & Reusable & Disposable \\
\hline Wired or wireless & $\begin{array}{l}\text { Wired, direct connection is } \\
\text { essential }\end{array}$ & $\begin{array}{l}\text { Some hospitals have a } \\
\text { wireless TOCO (telemetry) }\end{array}$ & $\begin{array}{l}\text { Most do not (yet) provide } \\
\text { wireless connection }\end{array}$ \\
\hline Potential risks or side-effects & $\begin{array}{l}\text { Moderate, }<1: 1,000, \text { rare } \\
\text { though severe complications } \\
\text { (placental/uterine } \\
\text { perforation) }\end{array}$ & $\begin{array}{l}\text { Very low, skin reactions due } \\
\text { to the transducer or elastic } \\
\text { band around the abdomen }\end{array}$ & $\begin{array}{l}\text { Low, skin reactions due to skin } \\
\text { preparation or the abdominal } \\
\text { electrodes }\end{array}$ \\
\hline Diagnostic values: & $\begin{array}{l}\text { Intrauterine pressure } \\
\text { catheter }\end{array}$ & External tocodynamometer & Electrohysterograph \\
\hline Accuracy of method & Very high & Moderate & High \\
\hline $\begin{array}{l}\text { Sensitivity contraction } \\
\text { detection }\end{array}$ & $>95 \%$ & $46-74 \%^{\mathrm{a}}$ & $86-98 \%^{\mathrm{a}}$ \\
\hline Sensitivity in obese women ${ }^{a}$ & $>95 \%$ & $46-51 \%^{\mathrm{a}}$ & $82-97 \%^{a}$ \\
\hline $\begin{array}{l}\text { Performance influenced } \\
\text { by second stage of labor }\end{array}$ & $\begin{array}{l}\text { Low, the catheter can be } \\
\text { expulsed }\end{array}$ & $\begin{array}{l}\text { Low, sensitivity might } \\
\text { increase as pushing improves } \\
\text { the uterine contact }\end{array}$ & $\begin{array}{l}\text { Moderate, potentially more } \\
\text { technical artifacts due to } \\
\text { pushing }\end{array}$ \\
\hline $\begin{array}{l}\text { Users' and patients' } \\
\text { preferences }\end{array}$ & $\begin{array}{l}\text { Intrauterine pressure } \\
\text { catheter }\end{array}$ & External tocodynamometer & Electrohysterograph \\
\hline Difficulty positioning & $\begin{array}{l}\text { Moderate, ultrasound for } \\
\text { placental localization and } \\
\text { vaginal examination }\end{array}$ & $\begin{array}{l}\text { Very low, can be easily placed } \\
\text { and adjusted throughout } \\
\text { labor }\end{array}$ & $\begin{array}{l}\text { Low, adequate skin } \\
\text { preparation is necessary }\end{array}$ \\
\hline Users' preference & $x$ & $35 \%$ & $40 \%$ \\
\hline Application & Moderate, score 31 & Low, score 10 & Very low, score 2 \\
\hline Presence during labor & Low, score 8 & Moderate, score 42 & Very low, score 2 \\
\hline Removal & Very low, score 5 & Very low, score 3 & Low, score 10 \\
\hline Patients' preference & $17 \%$ & $2 \%$ & $81 \%$ \\
\hline
\end{tabular}

Note: Scale: very low, low, moderate, high, very high; 0-100: $0=$ not bothering, $100=$ very bothering $\mathrm{x}$; not assessed.

asource references are ${ }^{3,5,19-21}$ 
adjustments (on average 0.5 per 2 -hour registration), including resetting baseline, flushing and repositioning of the catheter. In 3 cases the IUPC was expulsed and in 2 of these cases a new catheter had to be inserted.

Another important factor considering time-efficiency is, whether the method can be applied throughout the different stages of labor (term/preterm labor, first/second stage, with/ without ruptured membranes). The IUPC can only be inserted, when membranes are ruptured, which is not always the situation during the early stage of labor or during preterm labor. During second stage of labor the IUPC catheter can be pushed out. On the contrary, both EHG and TOCO do not require ruptured membranes. These techniques can already be applied in the early beginning of (preterm) labor and they stay positioned throughout labor and delivery. For women, this will be more convenient and for nurses this could improve workflow. Another factor that could influence time-efficiency is interpretability of uterine monitoring techniques. The adhesive properties of EHG enable a more continuous CTG registration of good quality that could be less time-consuming during labor. Previous studies have also shown that EHG registrations have a higher interpretability and are easier to interpret than TOCO. ${ }^{4,19,26}$

\section{Individualized Choice of Monitoring Method}

Most of above described factors depend on type of patient and situation. Therefore, these factors should be considered, when choosing a suitable method for uterine monitoring. Patients that benefit most from registration with EHG, TOCO, or IUPC could be selected. An overview of these methodspecific characteristics is presented in -Table 4 .

\section{Implementation}

The nurses of our hospital have been working with EHG for a couple of years now. As they were the first to work with this real-time method worldwide, they are the so-called "early adopters" in the "technology adoption life cycle" of the innovation theory described by Rogers. ${ }^{27}$ As for many innovations, there is still a chasm to be crossed. We expect that wide implementation of this technology may take some time. Experience needs to grow and investment in training is important. All future users should be trained on key aspects of EHG. Correct patch localization is important for proper interface with the myometrium and adequate skin preparation with abrasive sandpaper is essential for an accurate EHG signal. However, abrading too firm might evoke dermatologic reactions. Therefore, an impedance meter is useful to check impedances and guide users in preparation and application. As this step is considered time-consuming, it would be interesting to implement direct feedback on the EHG monitor with respect to skin impedance. Finally, for a successful implementation, it is essential that obstetricians will be trained in interpretation of EHG signals as well.

\section{Conclusion and Future Perspectives}

Current uterine monitoring techniques have some disadvantages. EHG is therefore being evaluated as a promising new method that is both safe and reliable. Patients prefer EHG over TOCO and IUPC, although the opinion of healthcare providers is inconclusive.

For future designs of EHG devices, we would recommend a waterproof and wireless system, enabling a more continuous and mobile monitoring. Integrating an impedance meter is also advised. These adjustments could further improve patients' and users' satisfaction, which is necessary for successful implementation in clinic. The effect of EHG application on obstetric and perinatal outcome and related cost-effectiveness should be further evaluated.

\section{Conflict of Interest}

The study has been financially supported by the Dutch Foundation "Stichting De Weijerhorst" and the Horizon2020 grant, the European Framework Program for Research and Innovation (Project number 719500). Author S.G.O. initiated the scientific research from Nemo Healthcare and from where the described EHG device have originated. There are no financial relationships between Nemo Healthcare and any of the authors.

\section{Acknowledgments}

None.

\section{References}

1 Bakker JJH, Janssen PF, van Halem K, et al. Internal versus external tocodynamometry during induced or augmented labour. (Review)Cochrane Database Syst Rev 2013;(08):CD006947

2 Bakker JJ, Verhoeven CJ, Janssen PF, et al. Outcomes after internal versus external tocodynamometry for monitoring labor. N Engl J Med 2010;362(04):306-313

3 Euliano TY, Nguyen MT, Darmanjian S, et al. Monitoring uterine activity during labor: a comparison of 3 methods. Am J Obstet Gynecol 2013;208(01):66.e1-66.e6

4 Hadar E, Biron-Shental T, Gavish O, Raban O, Yogev Y. A comparison between electrical uterine monitor, tocodynamometer and intra uterine pressure catheter for uterine activity in labor. J Matern Fetal Neonatal Med 2015;28(12):1367-1374

5 Vlemminx MWC, Thijssen KMJ, Bajlekov GI, Dieleman JP, Van Der Hout-Van Der Jagt MB, Oei SG. Electrohysterography for uterine monitoring during term labour compared to external tocodynamometry and intra-uterine pressure catheter. Eur J Obstet Gynecol Reprod Biol 2017;215:197-205

6 Panelli D, Teplick F, McCarthy M, Hebert S. Comparing methods to secure external fetal-monitoring devices. MCN Am J Matern Child Nurs 2014;39(01):41-47, quiz 48-49

7 Bakker PCAM, Zikkenheimer M, van Geijn HP. The quality of intrapartum uterine activity monitoring. J Perinat Med 2008;36 (03):197-201

8 Devedeux D, Marque C, Mansour S, Germain G, Duchêne J. Uterine electromyography: a critical review. Am J Obstet Gynecol 1993; 169(06):1636-1653

9 Tam HW, Webster JG. Minimizing electrode motion artifact by skin abrasion. IEEE Trans Biomed Eng 1977;24(02):134-139

10 Bakker PCAM, Van Rijswijk S, van Geijn HP. Uterine activity monitoring during labor. J Perinat Med 2007;35(06):468-477

11 Wilmink FA, Wilms FF, Heydanus R, Mol BWJ, Papatsonis DNM. Fetal complications after placement of an intrauterine pressure catheter: a report of two cases and review of the literature. J Matern Fetal Neonatal Med 2008;21(12):880-883 
12 Rothman KJ, Boice JD. Epidemiological Analysis with a Programmable Calculator. USA: NIH Publication; 1979

13 Wilson EB. Probable inference, the law of succession, and statistical inference. J Am Stat Assoc 1927;22(158):209-212

14 Fetal monitoring. Guidelines; perinatology. Dutch Society for Obstetrics and Gynecology. Version 30. 2015

15 Ayres-de-Campos D, Spong C, Chandraharan E. FIGO consensus guideline on intrapartum fetal monitoring. Int J Gynaecol Obstet 2015;131((01):13-24

16 American College of Obstetrics and Gynecology Committee on Practice Bulletins-Obstetrics. ACOG practice bulletin number 49, December 2003: dystocia and augmentation of labor. Obstet Gynecol 2003;102(49):1445-1454

17 Namm JP. Primum Non Nocere: Ethical Implications in Medical Innovation. Am J Bioeth 2016;16(07):72-73

18 Rood KM. Complications associated with insertion of intrauterine pressure catheters: an unusual case of uterine hypertonicity and uterine perforation resulting in fetal distress after insertion of an intrauterine pressure catheter. Case Rep Obstet Gynecol 2012; 2012:517461

19 EulianoTY, Nguyen MT, Darmanjian S, Busowski JD, Euliano N, Gregg AR. Monitoring uterine activity during labor: clinician interpretation of electrohysterography versus intrauterine pressure catheter and tocodynamometry. Am J Perinatol 2016;33(09):831-838
20 Cohen W, Hayes-Gill B, Hassan S, et al. Accuracy and reliability of uterine contraction identification using abdominal surface electrodes. Clin Med Insights Womens Health 2012;5:65-75

21 Euliano T, Skowronski M, Marossero D, Shuster J, Edwards R. Prediction of intrauterine pressure waveform from transabdominal electrohysterography. J Matern Fetal Neonatal Med 2006;19 (12):811-816

22 Simpson KR, James DC. Effects of oxytocin-induced uterine hyperstimulation during labor on fetal oxygen status and fetal heart rate patterns. Am J Obstet Gynecol 2008;199(01):34.e1-34. e5

23 Bakker PCAM, van Geijn HP. Uterine activity: implications for the condition of the fetus. J Perinat Med 2008;36(01):30-37

24 Cohen WR, Schifrin BS. Medical negligence lawsuits relating to labor and delivery. Clin Perinatol 2007;34(02):345-360, vii-viii

25 Lawrence A, Lewis L, Hofmeyr GJ, Dowswell T, Styles C. Maternal positions and mobility during first stage labour. Cochrane Database Syst Rev 2013. Doi: 10.1002/14651858.CD003934.pub4

26 Reinhard J, Hayes-Gill BR, Schiermeier S, et al. Uterine activity monitoring during a multi-centre, blinded two-way trial of external tocodynamometry against electrohysterography. Z Geburtshilfe Neonatol 2011;215(05):199-204

27 Rogers EM. Diffusion of Innovations. 5th ed. New York, NY: Simon and Schuster; 2003 